\title{
Study of pregnancy induced hypertension in relation to placental and fetal birth weight
}

\author{
Deepti Gupta*, Shabana Khan, Nazia Noor, Meena Bhargava
}

Department of Obstetrics and Gynecology, Index Medical Collage, Indore, Madhya Pradesh, India

Received: 15 January 2018

Accepted: 10 February 2018

\section{*Correspondence:}

Dr. Deepti Gupta,

E-mail: drspnagariya@gmail.com

Copyright: (c) the author(s), publisher and licensee Medip Academy. This is an open-access article distributed under the terms of the Creative Commons Attribution Non-Commercial License, which permits unrestricted non-commercial use, distribution, and reproduction in any medium, provided the original work is properly cited.

\begin{abstract}
Background: A healthy placenta is the most important factor in producing a healthy baby. Placenta which is the most important organ for maintaining and continuing healthy pregnancy and fetal growth. Study aimed to evaluate Pregnancy induced hypertension in relation to placental and fetal birth weight.

Methods: Total 200 mothers participated in the study, various parameters related with placental and fetal weight were calculated and analysed.

Results: This study observed the reduction of placental weight in the hypertensive disorders. Placental weight shows marked variation in all the groups and coefficient of variation was higher in severe PIH group, but mean weight was less with increased severity of PIH. Baby weight shows marked variation in all the groups and coefficient of variation was increased with severity of PIH and mean weight was less with increased severity of PIH. Placental weight was significantly reduced in pre-eclamptic pregnancies and it was directly correlated with fetal birth weight.

Conclusions: Hypertensive disorders of pregnancy adversely influence the placental weight, which ultimately, adversely influence the maternal and perinatal outcomes.
\end{abstract}

Keywords: Birth weight, Fetal, Hypertension, Pregnancy, Placenta

\section{INTRODUCTION}

A healthy placenta is the most important factor in producing a healthy baby. Placenta which is the most important organ for maintaining and continuing healthy pregnancy and fetal growth. It has two components: the fetal placenta (Chorion frondosum), which develops from the same blastocyst that forms the fetus, and the maternal placenta (Decidua basalis), which develops from the maternal uterine tissue. ${ }^{1}$

During the gestational period, it provides nutrition, gas exchange, waste removal, endocrine, immune support and a special circulation system to the developing fetus. ${ }^{2,3}$ Careful examination of the placenta can provide insight regarding the in utero environment of the fetus before delivery and therefore assessment of placenta is getting more importance in modern obstetrics and such placental changes can be an "early warning system" for fetal problems. $^{4}$

Placental weight and its relationship to infant size at birth have been studied in past which indicated that placental weight was associated with pregnancy outcome. High placenta weight was associated with a poor perinatal outcome, a low Apgar score, respiratory distress syndrome and perinatal death; whereas a low placental weight was associated with medical complications in the mother. ${ }^{5}$

Pregnancy-induced hypertension is the general classification for hypertension diseases during pregnancy, which include pregnancy-induced hypertension (without proteinuria), pre-eclampsia (with proteinuria), and 
eclampsia (pre-eclampsia with convulsions). This disease is responsible for high maternal and perinatal morbidity and mortality rates and is one of the main public health problems. $^{6,7}$ It is also estimated that pregnancy induced hypertension $(\mathrm{PIH})$, one of the hypertensive disorders of pregnancy, affects about $5-8 \%$ of all pregnant women worldwide. $^{8}$

Toxemia of pregnancy or pregnancy induced hypertension (PIH) is one of the fore most cause of death among mothers and foetuses. Various studies on placenta have shown that placental weight is directly related to foetal weight. Placenta in PIH mothers is irregular, small in size with marginal attachment of umbilical cord. Hence, this study is undertaken to evaluate the effects of hypertension on placental and fetal birth weight and to correlate their relationship.

\section{METHODS}

It is a prospective, observational study conducted in the department of Obstetrics and Gynecology, Index medical college, Indore, Madhya Pradesh, during the period of September 2015 to October 2016. Study was conducted on 200 placentae collected from labor room and operating theatre. Informed consent was obtained from all women who were enrolled in study.

The mothers were studied clinically for height, weight, blood pressure, pulse etc. along with recording of their medical history. Their lab investigation reports were noted. The placenta with cord and membranes were collected and observed immediately after the delivery. Any abnormality of the umbilical cord and membrane was noted.

\section{Inclusion criteria}

Cases of hypertensive disorders of pregnancy like

- Mild pregnancy induced hypertension

- Severe pregnancy induced hypertension

- Eclampsia.

\section{Exclusion criteria}

- Gestational hypertension

- Chronic hypertension

- Twin pregnancies

- Gestational age <36 weeks or $>42$ weeks.

Study was carried in two groups one is control and other is study group. Control group consist of 100 Placenta belonging to normotensive women.Study group consist of 100 placenta belonging to hypertensive disorder which were again divided into.

- Study group A- Mild PIH - Patients having diastolic blood pressure more than 90 and less than $100 \mathrm{~mm}$ of
$\mathrm{Hg}$, proteinuria (Traces to $1+$ ) with minimal liver enzyme elevation.

- Study group B- Severe PIH - Patients having a diastolic pressure of $110 \mathrm{~mm}$ of $\mathrm{Hg}$ or more, proteinuria $(2+$ or more), visual disturbances, headache, oliguria, elevated serum creatinine, hyperbilirubinemia, thrombocytopenia, marked elevation of liver enzymes with pulmonary edema.

- Study group C- Eclampsia- patients had most of the features of severe PIH with convulsions.

Placentae with umbilical cord and membranes were collected immediately after delivery. In all cases, the amnion and chorion were trimmed from the placenta. The umbilical cord was cut at a distance of 5 centimeters from the site of insertion. Placenta was washed in running tap water, dried with the help of blotting paper and weighed. The placentae along with the umbilical cord identified by corresponding code number and were preserved in $10 \%$ formalin solution for 48 hours for fixation.

Placental measurements were done in the same way as mentioned in previous studies. Once fixed, placentae were measured on a weighing machine graduated in grams (gm) and diameter was measured with the help of a measuring tape in centimeters. Weight of newborn was recorded from hospital record and feto-placental weight ratio was calculated. Placental coefficient was calculated by the following formula: Placental coefficient=placental weight in grams / birth weight in grams.

\section{Statistical analysis}

The data were statistically analyzed by using Statistical Package for Social Sciences (SPSS). The values of continuous variables were presented as mean values.

\section{RESULTS}

Total 200 placentae were evaluated, 100 were from pregnancy induced hypertension and remaining 100 are from normal group patients.

Table 1: Distribution of cases as parity.

\begin{tabular}{|lll|ll|}
\hline Type of cases & \multicolumn{2}{l|}{$\begin{array}{l}\text { Primigravida } \\
\text { No. of } \\
\text { cases }\end{array}$} & $\begin{array}{l}\text { Multigravida } \\
\text { No. of } \\
\text { cases }\end{array}$ & $\%$ \\
\hline Control (n-100) & 52 & 52 & 48 & 48 \\
\hline Mild PIH (n-61) & 33 & 54.09 & 28 & 45.91 \\
\hline Severe PIH (n-28) & 14 & 50 & 14 & 50 \\
\hline Eclampsia (n-11) & 06 & 54.54 & 05 & 45.45 \\
\hline
\end{tabular}

In pregnancy induced hypertension group $61 \%$ have mild PIH, $28 \%$ have severe PIH and $11 \%$ have eclampsia shows that out of 100 normotensive subjects, Table 1 shows that out of 200 cases, $52 \%$ constituted primigravida and $48 \%$ constituted multigravida. 
Among mild PIH cases $54.09 \%$ cases were primigravida and only $45.91 \%$ were multigravida whereas in severe $\mathrm{PIH}$ the distributions were $50 \%$ each. In eclamsia cases
$54.54 \%$ were primigravida and $45.45 \%$ were multigarvida.

Table 2: Distribution of cases as per age group.

\begin{tabular}{|lllllllll|} 
Age group & Control & \multicolumn{3}{c}{ Mild PIH } & \multicolumn{3}{c}{ Severe PIH } & \multicolumn{3}{c|}{ Eclampsia } \\
& $\mathbf{n - 1 0 0}$ & $\mathbf{\%}$ & $\mathbf{n - 6 1}$ & $\mathbf{\%}$ & $\mathbf{n - 2 8}$ & $\mathbf{\%}$ & $\mathbf{n - 1 1}$ & $\mathbf{\%}$ \\
\hline $17-20$ & 25 & 25 & 15 & 24.59 & 10 & 35.71 & - & - \\
\hline $21-24$ & 18 & 18 & 12 & 19.67 & 06 & 21.42 & 02 & 18.18 \\
\hline $25-28$ & 42 & 42 & 28 & 45.90 & 09 & 32.14 & 03 & 27.27 \\
\hline $29-32$ & 15 & 15 & 06 & 9.83 & 03 & 10.71 & 06 & 54.54 \\
\hline
\end{tabular}

Table 2 shows majority subjects in control group (42\%) and mild PIH (45.9\%0 were belonged to 25-28 age group while $35.71 \%$ in severe PIH of $17-20$ age group and $54.54 \%$ of eclampsia group belongs to $29-32$ age group.

Table 3 shows placental weight in $69 \%$ of normotensive group and $50.81 \%$ of mild PIH group was ranging between 501-600 grams while $42.85 \%$ of severe PIH and
$54.54 \%$ of eclampsia group was ranging between $301-$ 400 grams.

Table 4 shows fetal weight in normotensive subjects was ranging between $2500-3000$ grams in $79 \%$ and above 3000 grams in $12 \%$ while in mild PIH group $80.32 \%$ were ranging 2500-3000 grams. Fetal weight of majority patients of severe PIH group (64.28\%) and eclampsia (72.72\%) were below 2500 grams.

Table 3: Distribution of cases as per placental weight.

\begin{tabular}{|c|c|c|c|c|c|c|c|c|}
\hline \multirow[t]{2}{*}{ Placenta weight (gms) } & \multicolumn{2}{|c|}{ Control } & \multicolumn{2}{|c|}{ Mild PIH } & \multicolumn{2}{|c|}{ Severe PIH } & \multicolumn{2}{|c|}{ Eclampsia } \\
\hline & n-100 & $\%$ & n-61 & $\%$ & n-28 & $\%$ & n-11 & $\%$ \\
\hline$<300$ & - & - & - & - & 01 & 3.57 & 03 & 27.27 \\
\hline $301-400$ & - & - & 09 & 14.75 & 12 & 42.85 & 06 & 54.54 \\
\hline $401-500$ & 19 & 19 & 21 & 34.42 & 11 & 39.28 & 02 & 18.18 \\
\hline $501-600$ & 69 & 69 & 31 & 50.81 & 06 & 21.42 & - & - \\
\hline$>601$ & 12 & 12 & - & - & - & - & - & - \\
\hline
\end{tabular}

Table 4: Distribution of cases as per fetal weight.

\begin{tabular}{|lllllllll|}
\hline Fetal weight $(\mathrm{kg})$ & Control & & Mild PIH & \multicolumn{3}{c|}{ Severe PIH } & \multicolumn{3}{c|}{ Eclampsia } \\
\hline & $\mathbf{n - 1 0 0}$ & $\mathbf{\%}$ & $\mathbf{n - ~ 6 1}$ & $\mathbf{\%}$ & $\mathbf{n - 2 8}$ & $\mathbf{\%}$ & $\mathbf{n - 1 1}$ & \% \\
\hline$<2.5$ & 09 & 9 & 09 & 14.75 & 18 & 64.28 & 08 & 72.72 \\
\hline $2.5-3$ & 79 & 79 & 49 & 80.32 & 10 & 35.71 & 03 & 27.27 \\
\hline$>3$ & 12 & 12 & 03 & 4.91 & - & - & - & - \\
\hline
\end{tabular}

Table 5: Comparison of mean fetal weight, mean placental weight, feto-placental ratio and placental coefficient.

\begin{tabular}{|lllllllll|}
\hline Fetal weight $(\mathrm{kg})$ & Control & & Mild PIH & \multicolumn{3}{c|}{ Severe PIH } & \multicolumn{3}{c|}{ Eclampsia } \\
\hline & $\mathbf{n - 1 0 0}$ & $\mathbf{\%}$ & $\mathbf{n - 6 1}$ & $\mathbf{\%}$ & $\mathbf{n - 2 8}$ & $\mathbf{\%}$ & $\mathbf{n - 1 1}$ & $\mathbf{\%}$ \\
\hline$<2.5$ & 09 & 9 & 09 & 14.75 & 18 & 64.28 & 08 & 72.72 \\
\hline $2.5-3$ & 79 & 79 & 49 & 80.32 & 10 & 35.71 & 03 & 27.27 \\
\hline$>3$ & 12 & 12 & 03 & 4.91 & - & - & - & - \\
\hline
\end{tabular}

Table 5 shows the average feto-placental weight ratio, in normal pregnancy is 5.50, whereas in mild PIH, severe $\mathrm{PIH}$ and eclampsia group, it is $6.01,6.20$ and 6.08 respectively.
In present study, average placental coefficient is 0.163 in pre-eclamptic group and 0.181 in control group, which coincides with the normal value. 


\section{DISCUSSION}

A systematic examination of placenta is often ignored by the physician, gynecologist, pediatrician and pathologist in spite of its very useful role in the fetal development. The placenta has been described as a "diary of intrauterine life" and it may elucidate many aspects of intra uterine life.

Fetal birth weight can be influenced by both endogenous and exogenous factors. These factors include gestational age at delivery, physiological factors (altered glucose metabolism, hemoglobin concentration, macro vascular integrity), pathological factors (hypertension, uterine malformation), and complications of pregnancy (gestational diabetes mellitus, preeclampsia. ${ }^{9}$

Out of 200 placenta evaluated, 100 were from normotensive patients and 100 were from hypertensive group out of which mild PIH $(61 \%)$ is found in majority compared to severe PIH and Eclampsia. On assessment of parity, hypertensive disorder more in primi-gravida especially in eclamsia group (54.54). This is in concordance with study done by Maqueo $\mathrm{M}$ et al, who observed that incidence of eclampsia is more common in primigravida. ${ }^{10}$

Majority subjects in control group and mild PIH were belonged to 25-28 age group while, in severe PIH 17-20 age group and in eclampsia group 29-32 age group. Maqueo $\mathrm{M}$ et al observed that increased incidence of hypertensive disordered seen in early age group, which is also seen in this study except eclampsia. ${ }^{10}$

In the present study, weight of the placenta is decreases as severity of hypertension increase when compared with control group. This is in accordance with Das B et al, who observed that placental weight was significantly reduced where the duration of hypertensive disorders were prolonged. Although the still births were not significantly observed in this study, Udainia A et al observed that there was a significant lowering of placental weight in pregnancy induced hypertension. Low birth weight was associated with low placental weight. ${ }^{11,12}$ In placentae weighing less than 300 gms fetal birth weight was low and associated with fetal asphyxia which is significantly correlates with the severity of pregnancy induced hypertension. Present study shows, the mean birth weight and mean placental weight were low with increasing grades of hypertension compared to controls which is in accordance with the study of Das B et al and Mohan $\mathrm{H}$ et al. ${ }^{4,13}$

The feto-placental unit was adversely affected in pregnancy induced hypertension. Due to placental insufficiency the fetal growth was affected. Correlation of the fetal weight and placental weight is assessed by fetoplacental weight ratio. The ratio of the fetal weight to the placental weight is known as the feto-placental weight ratio, which is normally $6: 1 .{ }^{14}$ In the present study, the average feto-placental weight ratio in normal pregnancy is 5.50, whereas in mild PIH, severe PIH and eclampsia group, it is $6.01,6.20$ and 6.08 respectively. These values correlate with the study done earlier by Salmani D et al. ${ }^{15}$ In the present study, the mean feto-placental weight ratio is higher in hypertensive group as compared to normal group. Placental coefficient which calculated by correlating the weight of the baby and placenta. The normal placental coefficient is $0.12-0.20$. In our study, average placental coefficient is 0.163 in pre-eclamptic group and 0.181 in control group, which coincides with the normal value. These values correlate with the study done earlier by Singh S et al and Raghunath $\mathrm{G}$ et al. ${ }^{16,17}$

\section{CONCLUSION}

From the present study it can be concluded that, the pregnancy induced hypertension adversely influences the weight of the placenta and foetal outcome. Thus, placenta acts as an effective index by examination of which we can predict the status of foetus in neonatal life as it can act as an indicator to the overall development of the foetus in PIH cases. The early measurements of placenta by non-invasive technique like ultrasonography will be helpful in early identification of at risk fetus and better management of such pregnancies.

\section{Funding: No funding sources \\ Conflict of interest: None declared \\ Ethical approval: Not required}

\section{REFERENCES}

1. Yetter JF. Examination of the placenta. Am Fam Phys. 1998 Mar;57(5):1045-54.

2. Kliman HJ. Behind every healthy baby is a healthy placenta. Parenthood Lost. Westport, CT: Bergin and Garvey. 2001:130-1.

3. Pijnenborg R, Bland JM, Robertson WB, Brosens I. Uteroplacental arterial changes related to interstitial trophoblast migration in early human pregnancy. Placenta. 1983 Dec;4(4):397-413.

4. Goyal M, Singh KN, Agarwal R, Patel L, Khare S. Correlation of prenatal ultrasound findings with placental pathology in high risk pregnancies. JEMDS. 2014;3(3):665-72.

5. Adair FL, Thelander H. A study of the weight and dimensions of the human placenta in its relation to the weight of the newborn infant. Am J Obstet Gynecol. 1925;10:172-205.

6. Chen XK, Wen SW, Smith G, Yang Q, Walker M. Pregnancy-induced hypertension is associated with lower infant mortality in preterm singletons. BJOG. 2006;113(5):544-51.

7. Brown MA, Hague WM, Higgins J, Lowe S, McCowan L, Oats J, Austalasian Society of the Study of Hypertension in Pregnancy et al. The detection, investigation and management of hypertension in pregnancy: full consensus statement. Aust N Z J Obstet Gynaecol. 2000;40(2):139-55. 
8. Arshad A, Pasha W, Khattak TA, Kiyani RB. Impact of pregnancy induced hypertension on birth weight of newborn at term. JRMC. 2011;15(2):113-5.

9. Wang Y, Lewis DF, Gu Y, Zhang Y, Alexander JS, Granger DN. Placental trophoblast-derived factors diminish endothelial barrier function. $\mathbf{J}$ Clini Endocrinol Metab. 2004 May;89(5):2421-8.

10. Maqueo M, Azuela JC, Vega MDDL. Placental pathology in eclampsia and preeclampsia. Obstet Gynecol. 1964;24(3):350-5.

11. Das B, Dutta D, Chakraborthy S, Nath P. Placental morphology in hypertensive disorders of pregnancy and its co-relation with fetal outcome. J Obstet Gynecol India. 1996:40-6.

12. Udainia A, Jain ML. Morphological study of placenta in pregnancy induced hypertension with its clinical relevance. J Anat Soc India. 2001;50:24-7.

13. Mohan H, Sodhi S, Mohan PS, Jaiswal TS, Nagpal K, Rathee S. Fetal correlation with placental pathology in toxemia of pregnancy. J Obstet Gynecol India. 1989:170-5.

14. Zakowski MI, Ramanathan S. Uteroplacental circulation and Respiratory gas exchange. In Brown B, editor. Shinder and Levinson's Anesthesia for
Obstetrics, 5th ed. Lippincott William and Wikins, a Wolters Kluwer Business; 2013:18.

15. Salmani D, Purushothaman S, Somashekara SC, Gnanagurudasan E, Sumangaladevi K, Harikishan R et al. Study of structural changes in placenta in pregnancy-induced hypertension. J Natural Science, Biol Med. 2014 Jul; 5(2):352-5.

16. Singh S, Gugapriya TS. A cross sectional morphometric study of hypertensive with normal placentae and its correlation with fetal outcome. Int $\mathbf{J}$ Anat Res. 2014;2(2):437-42.

17. Raghunath G, Vijayalakshmi VS. A study on the Morphology and the Morphometry of the Human Placenta and its Clinical Relevance in a population in Tamilnadu. J Clin Diagnos Res. 2011Apr;5(2):282-6.

Cite this article as: Gupta D, Khan S, Noor N, Bhargava M. Study of pregnancy induced hypertension in relation to placental and fetal birth weight. Int J Reprod Contracept Obstet Gynecol 2018;7:1149-53. 